
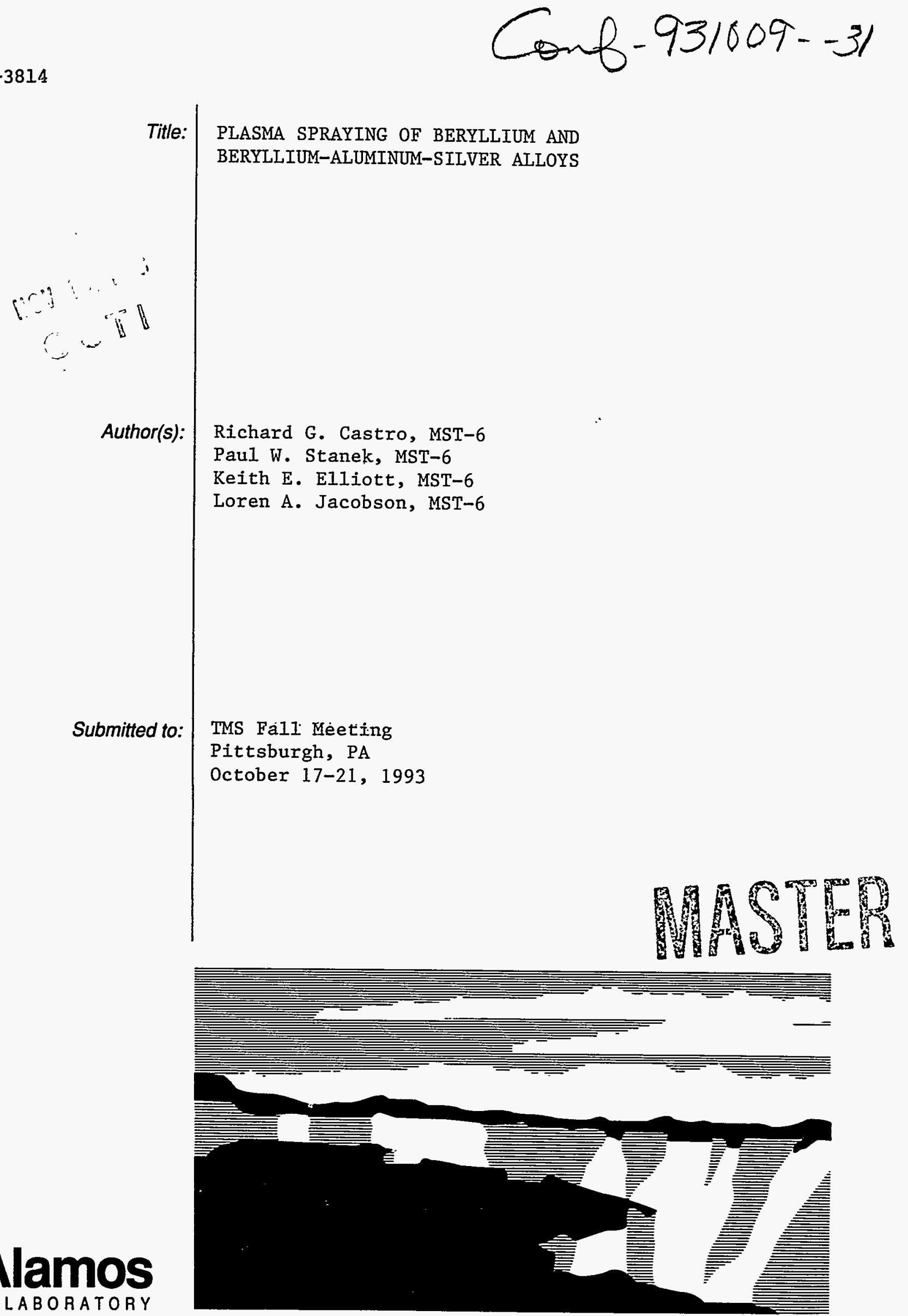

Los Alamos National Laboratory, an affirmative action/equal opportunity empldyer, is operated by the University of California for the U.S. Department of Energy under contract W-7405-ENG-36. By acceptance of this article, the publisher recognizes that the U.S. Government retains a nonexclusive, royalty-free license to publish or reproduce the published form of this contribution, or to allow others to do so, for U.S. Government purposes. The Los Alames National Laboratory requests that the publisher identify this article as work performed under the auspices of the U.S. Department of Energy. 


\title{
Plasma Spraying of Beryllium and Beryllium-Aluminum-Silver Alloys
}

\author{
R.G. Castro, P.W. Stanek, K.E. Elliott and L.A. Jacobson \\ Material Science and Technology Division \\ Los Alamos National Laboratory, Los Alamos, NM 87544
}

\begin{abstract}
A preliminary investigation on plasma-spraying of beryllium and a beryllium-aluminum$4 \%$ silver alloy was done at the Los Alamos National Laboratory's Beryllium Atomization and Thermal Spray Facility (BATSF). Spherical Be and Be-Al-4\%Ag powders, which were produced by centrifugal atomization, were used as feedstock material for plasma-spraying. The spherical morphology of the powders allowed for better feeding of fine $(<38 \mu \mathrm{m})$ powders into the plasma-spray torch. The difference in the as-deposited densities and deposit efficiencies of the two plasma-sprayed powders will be discussed along with the effect of processing parameters on the as-deposited microstructure of the $\mathrm{Be}-\mathrm{Al}-4 \% \mathrm{Ag}$. This investigation represents ongoing research to develop and characterize plasma-spraying of beryllium and beryllium-aluminum alloys for magnetic fusion and aerospace applications.
\end{abstract}

\section{DISCLAIMER}

\footnotetext{
This report was prepared as an account of work sponsored by an agency of the United States Government. Neither the United States Government nor any agency thereof, nor any of their bility for the accures any warranty, express or implied, or assumes any legal liability or responsiprocess disclosed, or represents that its usefulness of any information, apparatus, product, or ence herein to any specific commercial use would not infringe privately owned rights. Refermanufacturer, or otherwise does mendation, or favoring by the not necessarily constitute or imply its endorsement, recomand opinions of authors expressed States Government or any agency thereof. The views United States Government or any agency do not necessarily state or reflect those of the
} 


\section{DISCLAIMER}

Portions of this document may be illegible in electronic image products. Images are produced from the best available original document. 


\subsection{Introduction}

In May 1992, Los Alamos National Laboratory, Manufacturing Sciences Corporation of Oak Ridge, Tennessee, and Pratt \& Whitney of West Palm Beach, Florida entered into a Cooperative Research and Development Agreement (CRADA) to develop, implement, and use the products from advanced beryllium processing. This Advanced Beryllium Processing CRADA is directed at identifying improved beryllium and beryllium-alloy materials and processing methods along with an emphasis on adopting environmentally conscious manufacturing practices to reduce human exposure to beryllium particulate [1]. The process technologies being investigated include ingot metallurgy, powder atomization and consolidation, and low pressure plasma spray.

This paper reports on work in progress on plasma spray deposition of beryllium and beryllium-aluminum alloy powders. The plasma spray deposition process is also being evaluated as a potential method for fabricating and maintaining the plasma facing components (PFC's) in magnetic fusion energy devices. At present, beryllium is one of the materials being considered for plasma facing components for the International Thermonuclear Experimental Reactor (ITER), the next generation magnetic fusion energy device. The beryllium-aluminum alloys being developed and investigated at Los Alamos will provide potentially lower density, higher strength replacement materials for aluminum and titanium based components in aerospace applications.

\subsection{Experimental}

\subsection{Be-Al-Ag alloy powder production}

As part of the Advanced Beryllium Processing CRADA, Pratt \& Whitney has loaned an experimental centrifugal atomizer to Los Alamos to evaluate this atomization process for producing spherical beryllium and beryllium alloy powders to be used as feedstock materials for hot isostatic pressing and plasma spraying. The centrifugal atomization process, which is proprietary to $P \& W$, consists of vacuum induction melting a beryllium metal charge in a magnesia crucible and directing a stream of the molten metal onto the surface of a rapidly spinning disk, Figure 1. The liquid metal is mechanically atomized into finely divided droplets at the periphery of the disk. The droplets are solidified in flight inside the atomizing chamber by a transverse flow of helium gas which transports the powder product into a cyclone separator. This rapid solidification process produces spherical powder with solidification rates of $10^{4}-10^{6}$ degrees $\mathrm{C} / \mathrm{sec}$. The beryllium powder is collected in a canister below the cyclone separator, valved off, transferred to an inert-gas glove box, and screened and packaged for subsequent processing. The size distribution of the powder produced is strongly influenced by the physical characteristics of the molten charge along with various atomizer processing parameters including superheat and pour temperature, nozzle diameter, disk speed, and quench gas atmosphere. 
The melt stock used to produce the $\mathrm{Be}$ and $\mathrm{Be}-\mathrm{Al}-\mathrm{Ag}$ alloy powders consisted of high purity $(99.7 \%)$ vacuum cast beryllium lump purchased from Brush Wellman Inc., Elmore Ohio, aluminum ingot $(99.995 \%)$, and $(99.9 \%)$ silver shot. In this investigation, Be and Be-Al-Ag alloy powders below 400 mesh $(<38 \mu \mathrm{m})$ were used to produce the initial spray deposits. After the initial spray trials using the Be-Al-Ag alloy powders, a larger powder size fraction, -325 mesh $(<45 \mu \mathrm{m})$ was chosen due to the melting behavior and clogging of the powder injection ports. Characterization of both the $\mathrm{Be}$ and $\mathrm{Be}-\mathrm{Al}-\mathrm{Ag}$ powders was done using scanning electron microscopy and optical microscopy.

\subsection{Plasma-spraying of $\mathrm{Be}$ and $\mathrm{Be}-\mathrm{Al}-4 \% \mathrm{Ag}$}

Spray deposits of $\mathrm{Be}$ and a $\mathrm{Be}-\mathrm{Al}-4 \% \mathrm{Ag}$ alloy were made using the low pressure plasma spray chamber at Los Alamos National Laboratory's Beryllium Atomization and Thermal Spray Facility (BATSF). The plasma spray chamber contains a commercial SG-100 Plasmadyne torch which is mounted over a translating water-cooled copper substrate. Spray deposits of both the $\mathrm{Be}$ and the $\mathrm{Be}-\mathrm{Al}-4 \% \mathrm{Ag}$ were made on $(3.175 \mathrm{~mm})$ thick copper substrates which were translated back-and-forth under the plasma spray torch. Deposit thicknesses ranged from $7 \mathrm{~mm}$ to $14 \mathrm{~mm}$ after spraying for 5 minutes. Process parameters used in this investigation to deposit the $\mathrm{Be}$ and $\mathrm{Be}-\mathrm{Al}-4 \% \mathrm{Ag}$ are given in Table 1.

Table 1.

Operating parameters to produce plasma-spray deposits of $\mathrm{Be}$ and $\mathrm{Be}-\mathrm{Al}-4 \% \mathrm{Ag}$

\begin{tabular}{|c|c|c|}
\hline Parameters & Be & Be-Al-4\%Ag \\
\hline \hline Current (amps) & 700 & 500 \\
\hline Voltage (V) & 36.7 & 35.3 \\
\hline Primary arc gas (Ar) & $30 \mathrm{slm}$ & $30 \mathrm{slm}$ \\
\hline Auxiliary gas (He) & $15 \mathrm{slm}$ & $30 \mathrm{slm}$ \\
\hline Powder carrier gas (Ar) & $2.5 \mathrm{slm}$ & $2.5 \mathrm{slm}$ \\
\hline Powder feed rate & $.5 \mathrm{lb} / \mathrm{hr}$ & $.5 \mathrm{lb} / \mathrm{hr}$ \\
\hline Torch to substrate distance & $76.2 \mathrm{~mm}$ & $76.2 \mathrm{~mm}$ \\
\hline Substrate translation & $39 \mathrm{ipm}$ & $39 \mathrm{ipm}$ \\
\hline Atmosphere & $350 \mathrm{torr}$ & $500 \mathrm{torr}$ \\
\hline Anode/Cathode & $145 / 129$ & $730 / 129$ \\
\hline
\end{tabular}

The processing parameters used to produce the beryllium spray deposits were taken from a previous study by Castro et. al, which investigated the effect of processing parameters on the quality of plasma sprayed beryllium for magnetic fusion applications [2]. In this study, particle morphology, particle size distribution and the effect of various operating parameters (secondary gas addition, and chamber pressure) were investigated to determine their effect on the as-deposited density, deposit efficiency, and thermal conductivity. 
Deposit efficiencies (the fraction of material deposited on the substrate) was determined by measuring the weight of the substrate before and after depositing the $\mathrm{Be}$ and $\mathrm{Be}-\mathrm{Al}$ $4 \% \mathrm{Ag}$ alloy. The difference in weight was than compared to the total amount of powder dispensed during each plasma spray run. Since the beryllium and beryllium alloy powder is fed into the SG-100 spray torch using a weight/loss control system consisting of a commercial powder feed hopper on a Toledo weight scale, an accurate weight of powder present in the hopper before and after the spray operation could be determined.

Spray deposits of both the $\mathrm{Be}$ and $\mathrm{Be}-\mathrm{Al}-4 \% \mathrm{Ag}$ were removed from the copper substrates by bending the substrates until the deposits detached. As-deposited densities were determined using a water immersion technique and image analysis. Microstructural characterization in the as-deposited condition was accomplished using polarized light microscopy and scanning electron microscopy.

\subsection{Results and Discussion}

\section{1 $\mathrm{Be}$ and $\mathrm{Be}-\mathrm{Al}-\mathrm{Ag}$ powder production results}

Initial centrifugal atomization trials at Los Alamos focused on developing parameters for producing pure beryllium powders and beryllium containing minor binary additions such as yttrium and titanium. This development work successfully established atomizer operating parameters which converted up to $85 \%$ of a 2.5 kilogram melt charge into powder product. Following these initial investigations, the program has focused on developing beryllium-aluminum alloys with silver additions to strengthen the aluminum phase. These materials are variations on the Lockalloy compositions investigated by Lockheed Missiles and Space Company over 30 years ago [3]. Since the Be-Al system exhibits no solid solubility in beryllium, rapid cooling from the molten state produces a finely dispersed two phase structure of beryllium enveloped by a ductile aluminum matrix, Figure 2. The silver addition, which segregates entirely to the aluminum phase, permits strengthening of the aluminum phase through an age-hardening response. To date, Be-Al-Ag alloy powder compositions of $50 \mathrm{wt} . \% \mathrm{Be}$ and $2.5,3.0$, and $4.0 \mathrm{wt} \% \mathrm{Ag}$, balance $\mathrm{Al}$, have been produced for HIP consolidation and plasma spraying. The $2.5 \%$ silver alloy (HIP consolidated) has been solution heat treated and precipitation-aged to a hardness level of 120-155 Vickers Hardness Number. This hardness range is representative of high-strength aluminum alloys used in aerospace applications.

Plasma spraying of the $4.0 \mathrm{wt} . \% \mathrm{Ag}$ alloy was selected for this investigation due to the availability of the powder feedstock. A comparison of the powder morphology between the $\mathrm{Be}$ and the $\mathrm{Be}-\mathrm{Al}-4 \% \mathrm{Ag}$ is given in Figure $3 \mathrm{a}$ and $3 \mathrm{~b}$. In these figures, the beryllium powders showed a larger occurrence of fracturing of individual particles when compared to the $\mathrm{Be}-\mathrm{Al}-4 \% \mathrm{Ag}$ powders. The presence of the secondary $\mathrm{Al}-\mathrm{Ag}$ phase in the beryllium alloyed powders provides toughness and fracture resistance during the centrifugal atomization powder process. 
Similar atomization parameters, except for melt temperature at pour, were employed to produce both the $\mathrm{Be}$ and $\mathrm{Be}-\mathrm{Al}-4 \% \mathrm{Be}$ powders. The $\mathrm{Be}-\mathrm{Al}-4 \%$ alloy solidifies through a temperature range of about $645-1150^{\circ} \mathrm{C}$ compared to $1287^{\circ} \mathrm{C}$ for pure beryllium. Superheats ranging from $100-180^{\circ} \mathrm{C}$ above $1287^{\circ} \mathrm{C}$ and $1150^{\circ} \mathrm{C}$, respectively, were used for atomizing the $\mathrm{Be}$ and the $\mathrm{Be}-\mathrm{Al}-\mathrm{Ag}$ alloy powders. In general, the size distribution of the powder product from the atomizer consisted of about $50 \mathrm{wt} . \%$ 45-106 $\mu \mathrm{m}$ and $20 \mathrm{wt} . \%<45 \mu \mathrm{m}$ providing an adequate quantity of fine powder for the plasma spray investigations.

\subsection{Results of plasma-sprayed $\mathrm{Be}$ and $\mathrm{Be}-\mathrm{Al}-4 \% \mathrm{Ag}$}

The as-deposited microstructure of the $\mathrm{Be}$ and $\mathrm{Be}-\mathrm{Al}-4 \% \mathrm{Ag}$ which were produced using the processing parameters given in Table 1. are shown in Figure 4. The lower porosity levels and higher deposit density observed in the Be-Al-4\%Ag spray deposits resulted from better melting of the beryllium alloy powders during plasma spraying. In the case of the beryllium spray deposits, a higher population of unmelted or partially melted beryllium particles was observed. Closed porosity was observed in most cases next to the unmelted beryllium particles. The as-deposited density and corresponding deposit efficiency for both the $\mathrm{Be}$ and $\mathrm{Be}-\mathrm{Al}-4 \% \mathrm{Ag}$ spray deposits are compared in Figure 5. The beryllium in the as-deposited condition showed deposit densities on the order of $94 \%$ of theoretical with deposit efficiencies of approximately $60 \%$. In the case of the Be-Al$4 \% \mathrm{Ag}$ deposits, the as-deposited densities were approximately $99 \%$ of theoretical with deposit efficiencies of approximately $80 \%$. Increases in the deposit density and deposit efficiency of the plasma sprayed Be-Al-4\%Ag can be attributed to the increased melting paths associated with the more segregated microstructure of the beryllium alloy powders, Figure 2. Melting of the beryllium alloy powders can occur along the low melting intercellular $\mathrm{Al}-\mathrm{Ag}$ regions and subsequently proceed into the core of the powder producing a more completely melted population of powders. Depending on the cohesive nature of the powders, the powders may continue to melt as a sphere or separate along the intercellular regions during plasma spraying. If the particles tend to break apart they will subsequently melt at different rates then the original starting powders. This type of melting behavior is in contrast to the pure beryllium powders which will show a sharp transition from a completely solid particle to either a partially melted or fully melted particle. It is therefore reasonable to conclude that for a given change in temperature of the powder particles during plasma spraying a larger fraction of liquid will be present in the beryllium alloy powders. Similar results have been reported by Smith et. al., for plasma-sprayed nickel and nickel alloy powders done under a low pressure environment [4].

Because of the improved melting of the Be-Al-4\%Ag powder feedstock, the initial operating parameters were changed from those conditions which were used to spray pure beryllium. When spraying the Be-Al-4\%Ag using the Be operating conditions in Table 1, clogging of the plasma spray torch resulted. The operating current was subsequently 
reduced from 700 amps to 500 amps and a low velocity laminar flow anode and cathode configuration (730/129) was used in the plasma spray torch. This was done to allow for better injection of the $\mathrm{Be}-\mathrm{Al}-4 \% \mathrm{Ag}$ powders into the core of the plasma jet in order to prevent premature melting and clogging at the powder feed port. The chamber pressure was maintained at a 500 torr level in order to maximize the dwell time of the particles in the spray torch and a larger powder size, -325 mesh ( $<45 \mathrm{um})$ was used for plasma spraying.

Selected processing parameters were varied slightly to evaluate their effect on the melting behavior of the $\mathrm{Al}-\mathrm{Be}-4 \% \mathrm{Ag}$ powders. The primary and secondary plasma gas flow rates were decreased to $25 \mathrm{slm}$ in order slow down the velocity of the particles in the plasma jet and to increase the particles dwell time. Electron backscattered images of the plasma sprayed deposits under this condition are compared to spray deposits of $\mathrm{Be}-\mathrm{Al}-4 \% \mathrm{Ag}$ using the conditions specified in Table 1., Figure $6 \mathrm{a}$ and $\mathrm{b}$. From this variation, $a$ substantial change in the as-deposited microstructure was observed. The spray deposits which were produced using the 25 slm primary and secondary gas flow rates resulted in a coarser microstructure then the deposits which were produced using the 30 slm primary and secondary gas flow rates. Individual splat layers which make up the bulk of the spray deposit are easily detected in the deposits which were made using the $30 \mathrm{slm}$ gas flow rates. The fine microstructure associated with each splat layer is a result of the rapid solidification that occurs when an individual liquid particle impacts the surface of the deposit, spreads, and then solidifies. Solidification rates on the order of $10^{5}$ to $10^{6}$ ${ }^{\circ} \mathrm{C} / \mathrm{sec}$ can occur for each individual splat layer [5]. In contrast, the coarse microstructure exhibited in the Be-Al-4\%Ag deposits when using the $25 \mathrm{slm}$ gas flow rates did not show the presence of the individual splat layers. The resulting microstructure, which represents a slower solidification rate in the Be-Al-4\%Ag deposits, is not well understood but may be attributed to the reduced particle velocity and subsequent impacting of the molten beryllium alloy droplets. Within these deposits, porosity was also observed and and resulted from the inadequate flow of the $\mathrm{Al}-\mathrm{Ag}$ phase into closed regions which were surrounded by the primary beryllium phase. Further investigations to determine the effect of various processing parameters on the as-deposited microstructure of the $\mathrm{Al}-\mathrm{Be}-4 \% \mathrm{Ag}$ are currently in progress at Los Alamos. In addition, the stability of the fine microstructure is being evaluated after exposure to various times and temperatures.

\subsection{Summary}

- Spherical powders of Be and a Be-Al-4\%Ag alloy produced by centrifugal atomization were used as powder feedstock material for plasma spraying high density deposits of both the $\mathrm{Be}$ and $\mathrm{Be}-\mathrm{Al}-4 \% \mathrm{Ag}$.

- Plasma spraying of the Be-Al-4\%Ag powders resulted in higher deposit densities and deposit efficiencies due to the increased melting paths of the alloyed powders. 
- Because of the better melting of the $\mathrm{Be}-\mathrm{Al}-4 \% \mathrm{Ag}$ powders, particle size and operating conditions were changed in order to prevent clogging of the powder injection ports.

- Slight variations in the plasma spray parameters can significantly change the asdeposited microstructure in the $\mathrm{Be}-\mathrm{Al}-4 \% \mathrm{Ag}$ deposits.

\section{Acknowledgment}

This work was supported by the U.S. Department of Energy under CRADA Contract No. LC9110003, Advanced Beryllium Processing; the industrial partners in this CRADA, Manufacturing Sciences Corporation and Pratt \& Whitney.

\section{References}

1. P.W. Stanek, D.A. Cremers, R.G. Castro, L.A. Jacobson, and D.R. Floyd, "Environmentally Conscious Manufacturing of Beryllium", Int. J. of Environmentally Conscious Design and Manf, Vol.1 (2-4) (1992) 1-10.

2. R.G. Castro, P.W. Stanek, L.A. Jacobson, and D.F. Cowgill, "Effect of Processing Parameters on Plasma Sprayed Beryllium for Fusion Applications", Proceedings of the Beryllium Workshop for Fusion Applications, Karlsruhe, Germany October 4-5, 1993.

3. W.H. Santschi and W.G. Marz, Beryllium Technology, Volume 1, Conf. Session 1-4, Proceedings of the Second International Conference on Beryllium Technology, Ed., L. McDonald Schetky and H.A. Johnson, Gordon and Breach, Science Publishers, Inc., N.Y. (1966) 523.

4. R.W. Smith and D. Apelian, Mat. Res. Soc. Symp. Proc. Vol. 98 (1987), p. 89

5. M.R. Jackson, J.R. Rairden, J.S. Smith and R.W. Smith, J. of Metals, 33(11) (1981) 23-27. 


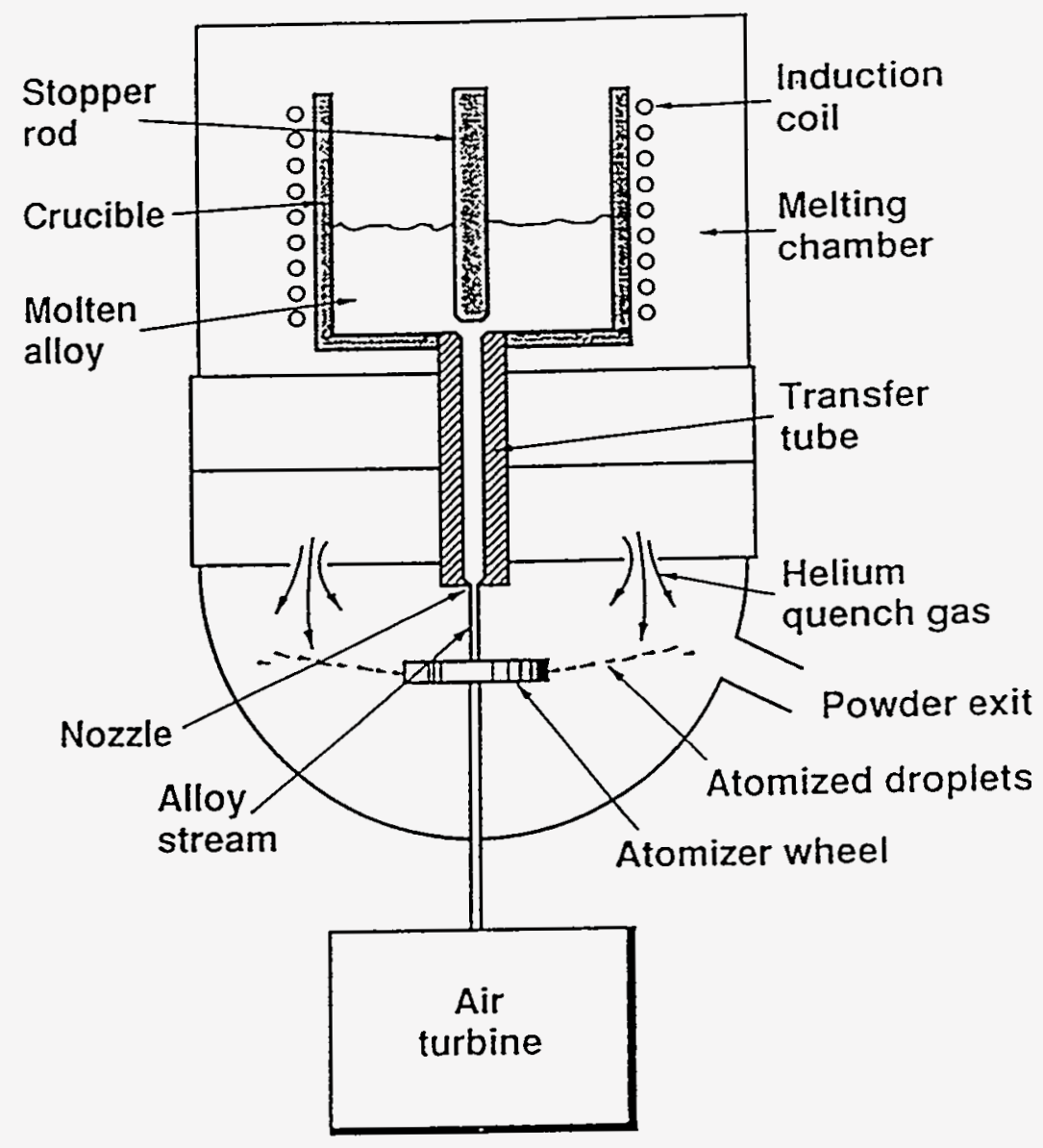

Figure 1. Schematic of the Pratt \& Whitney centrifugal atomization process. 


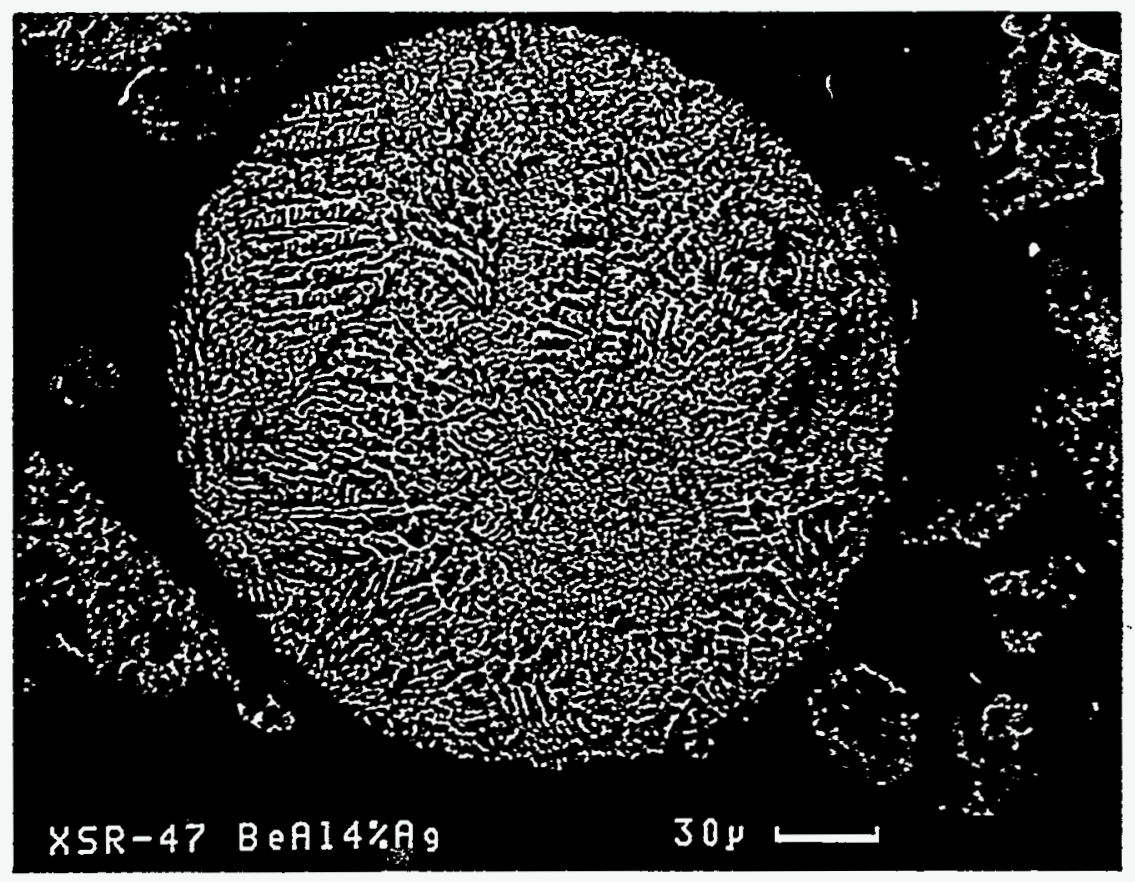

Figure 2. Microstructure of the centrifugal atomized $\mathrm{Be}-\mathrm{Al}-4 \% \mathrm{Ag}$ powders (dark phase beryllium - light phase $\mathrm{Al}-\mathrm{Ag}$ ) 

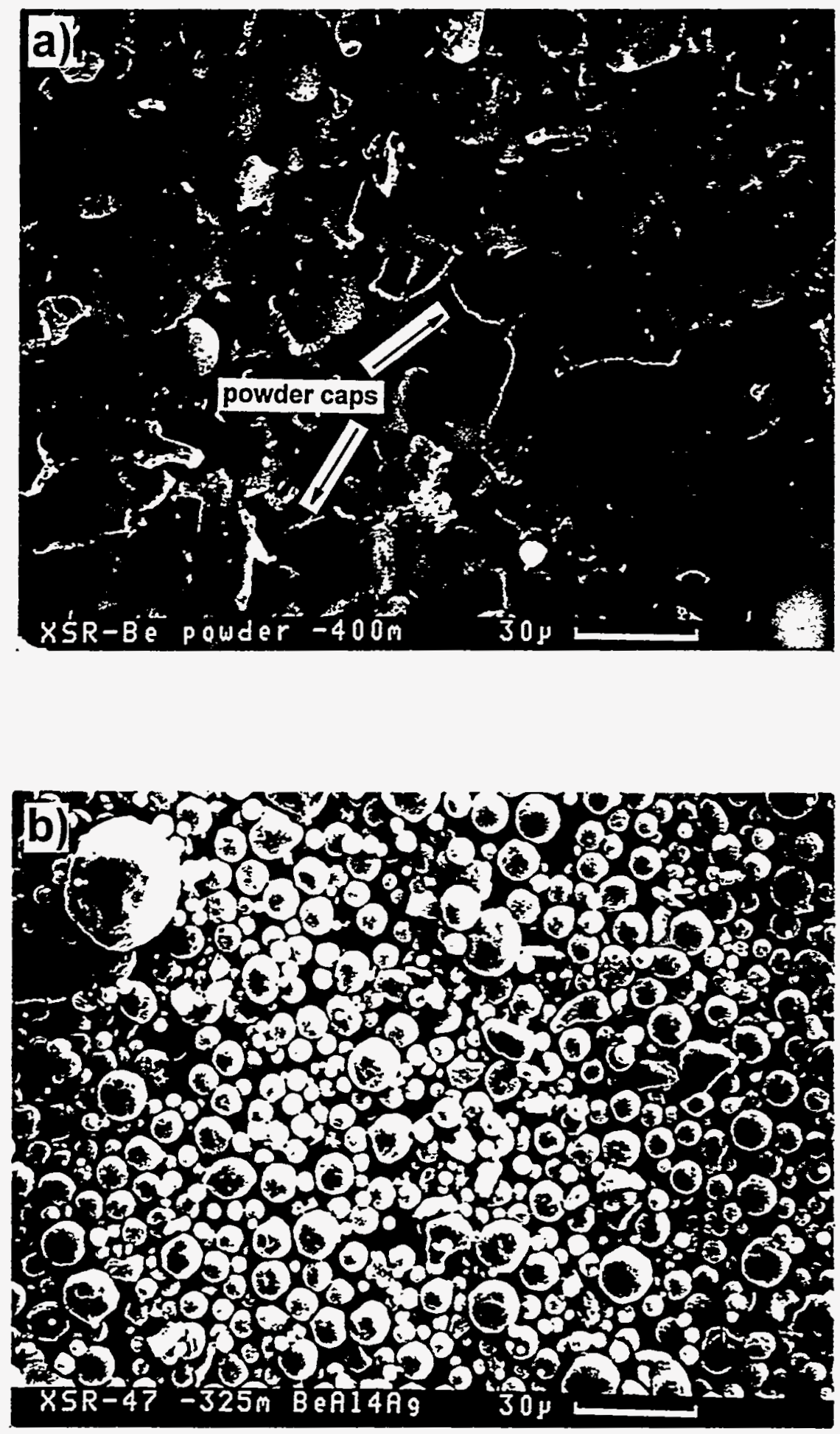

Figure 3. Powder morphology of the centrifugal atomized a) Be and b) Be-Al-4\%Ag. 

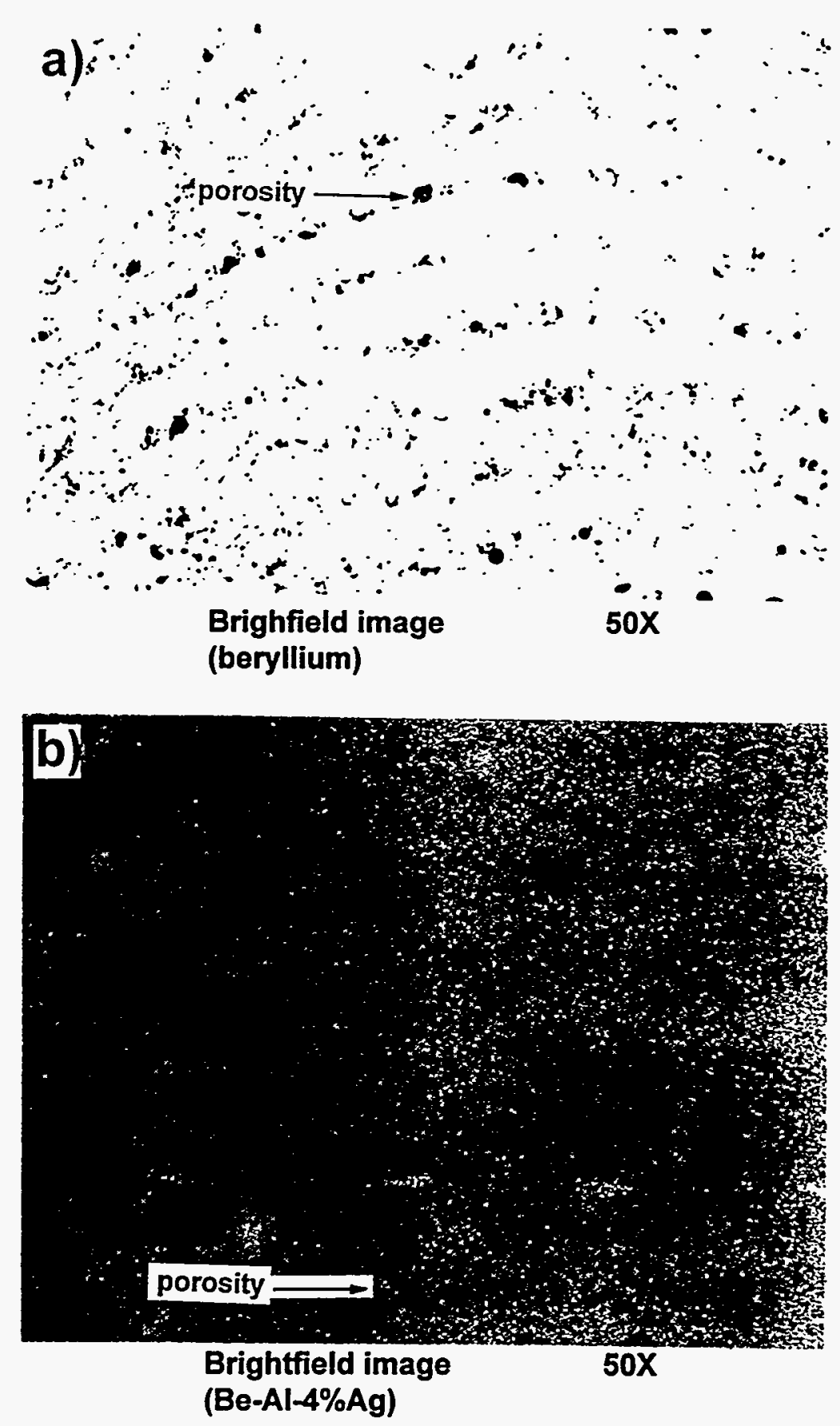

Figure 4. As-deposited microstructure of a) Be and b) Be-Al-4\%Ag showing the different levels of porosity in the spray deposits. 


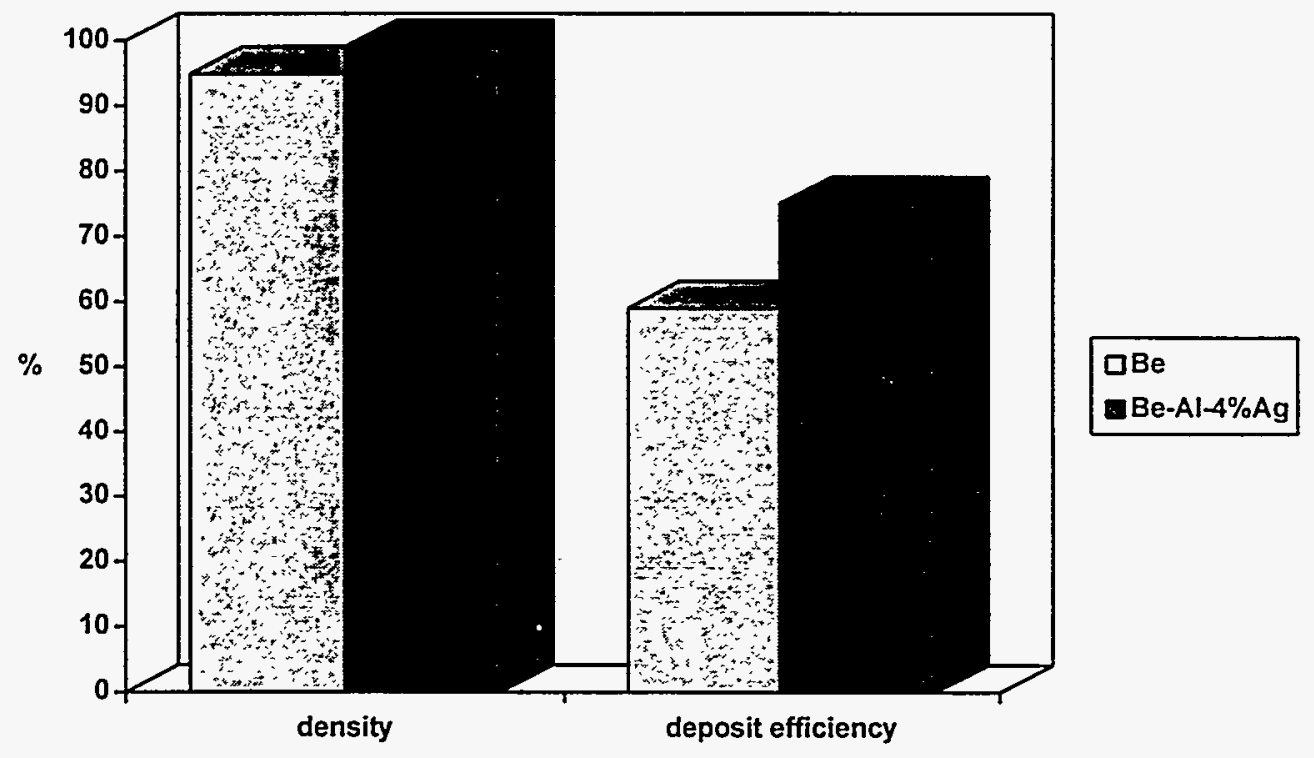

Figure 5. A comparison of the as-deposited density and deposit efficiency of plasma sprayed $\mathrm{Be}$ and $\mathrm{Be}-\mathrm{Al}-4 \% \mathrm{Ag}$. 

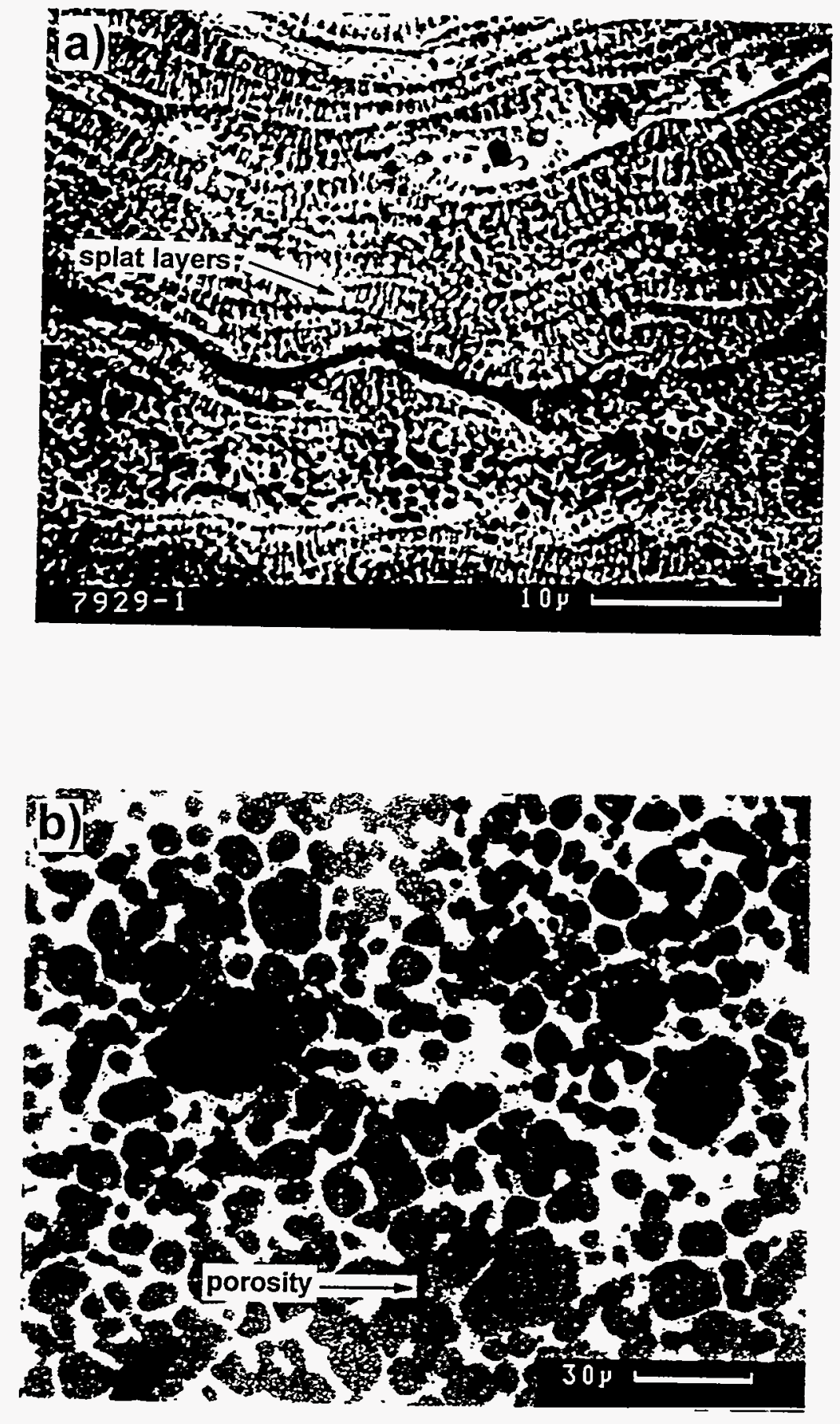

Figure 6. The effect of processing parameters on the as-deposited microstructure of Be$\mathrm{Al}-4 \% \mathrm{Ag}$. a) $30 \mathrm{slm}$ of the primary and secondary plasma gases, b) $25 \mathrm{sim}$ of the primary and secondary plasma gases. 